\title{
The Diagnosis and Management of Post Traumatic Syringomyelia
}

\author{
B. M. Lyons, M.B.B.S., ${ }^{1}$ D. J. Brown, F.R.A.C.P., ${ }^{2}$ J. M. Calvert, F.R.C.S. \\ F.R.A.C.S., ${ }^{3}$ J. M. Woodward, F.R.C.S., F.R.A.C.S., ${ }^{4}$ C. H. R. Wriedt, \\ D.M.R.D., F.R.C.R. ${ }^{5}$ \\ ${ }^{1}$ Lately Senior Surgical Resident, Spinal Injuries Unit Austin Hospital, Heidel- \\ berg, Melbourne, Australia, 3084. ${ }^{2}$ Medical Director, Spinal Injuries Unit. \\ ${ }^{3}$ Senior Neurosurgeon, Austin Hospital. ${ }^{4}$ Neurosurgeon, Austin Hospital. \\ ${ }^{5}$ Radiologist, Department of Diagnostic Radiology, Austin Hospital, Australia.
}

\section{Summary}

We have reviewed 21 cases with the clinical diagnosis of Post Traumatic Syringomyelia (P.T.S.). Fifteen of these cases had proven syrinx formation on Contrast Computed Tomography (C.C.T.) and the other 6 had obviously abnormal cords. A much earlier onset of P.T.C.M. was found in complete spinal injuries than in incomplete ones. We have discussed the technique of contrast computed tomography used at this hospital, its value in the diagnosis of this condition and its ability to define actual spinal cord structure. Most cases (91\%) benefitted from surgery and several had marked sensory improvement, which previously has been described as unusual. Syringo-cisternal shunting, a new technique for the drainage of cervical and upper thoracic syrinxes is described.

A theory is proposed to explain why, in some patients with classical presentations of P.T.S., no syrinx was found on C.C.T., although abnormal cords were found in all cases. It is felt that these abnormal areas of spinal cord are responsible for the presenting symptomatology and may be precursors of syrinxes.

Key words: Post traumatic syringomyelia (P.T.S.); Syringo-cisternal shunt.

\section{Introduction}

Progressive neurological deterioration as a sequel to post-traumatic cystic degeneration of the spinal cord is recognised as an infrequent occurrence after significant spinal cord injuries. The condition has been described under many titles, including post-traumatic syringomyelia, ascending cystic myelopathy and ascending cystic degeneration of the cord. We prefer the term post-traumatic syringomyelia (P.T.S.). The word syrinx is commonly used to describe a variety of cystic areas within the spinal cord.

With the advent of more sophisticated radiological techniques, e.g. contrast computed tomography (C.C.T.), it seems that this condition is being diagnosed more frequently. In addition, C.C.T. allows the diagnosis to be clarified in patients presenting with an identical clinical picture and enables surgery to be planned more rationally. 
Table I Baseline data (initial injury)

\begin{tabular}{|c|c|c|c|}
\hline Name & Mode of injury & Skeletal injury & Neurological lesion \\
\hline E.W. & MCA & $\mathrm{C} 5(\mathrm{~F}-\mathrm{S})$ & C5 (I) \\
\hline A.M. & MCA & T5 (F) & $\mathrm{T} 4(\mathrm{C})$ \\
\hline R.W. & MBA & C6-7 (F-D) & $\mathrm{C} 8(\mathrm{C})$ \\
\hline R.B. & MCA & $\mathrm{T} 7(\mathrm{~F})$ & T9 (I) \\
\hline T.L. & Fall & C5 $(F)$ & C5 (I) \\
\hline J.W. & Fall & T5-6 (F) & T6 (C) \\
\hline G.S. & MCA & $\mathrm{C} 4(\mathrm{~F})$ & C4-5 (I) \\
\hline J.B. & MBA & T6 (F) & T6 (C) \\
\hline S.H. & MCA & T7 (F) & $\mathrm{T} 8(\mathrm{C})$ \\
\hline C.M. & MCA & $\mathrm{T} 2,3,4(\mathrm{~F}-\mathrm{D})$ & $\mathrm{T} 2(\mathrm{C})$ \\
\hline M.L. & MBA & T5-6 (F-D) & T5 (C) \\
\hline P.G. & MBA & $\mathrm{C} 5,6,7(\mathrm{~F})$ & C5 (C) \\
\hline L.M. & MCA & T5 $(\mathrm{F})$ & $\mathrm{T} 12(\mathrm{I})$ \\
\hline W.C. & MCA & C3-4 (S) & $\mathrm{C} 3,4$ (I) \\
\hline D.T. & MCA & C5-6 (H) & C5 (I) \\
\hline J.F. & Diving & C5-6 (F-D) & $\mathrm{C} 8(\mathrm{I})$ \\
\hline K.C. & Fall & T12-L1 (F) & L1 (I) \\
\hline B.W. & MCA & $\mathrm{C} 4,6,7(\mathrm{~F})$ & $\mathrm{C} 7(\mathrm{C})$ \\
\hline G.T. & Diving & C4-5 (F-D) & C5 (C) \\
\hline M.B. & MCA & C6 (F-D) & C6 (C) \\
\hline A.C. & Convulsion & L1 (F) & L2 (C) \\
\hline $\begin{array}{l}\mathrm{MBA}= \\
\mathrm{MCA}=\end{array}$ & $\begin{array}{l}\text { tor bike accident } \\
\text { tor car accident }\end{array}$ & $\begin{array}{l}\mathrm{F}=\text { Fracture } \\
\mathrm{D}=\text { Dislocation } \\
\mathrm{S}=\text { Subluxation } \\
\mathrm{H}=\text { Hyper exten }\end{array}$ & $\begin{array}{l}(\mathrm{C})=\text { Complete } \\
(\mathrm{I})=\text { Incomplete }\end{array}$ \\
\hline
\end{tabular}

We report a group of patients, each of whom had good clinical evidence of P.T.S., and discuss the value of C.C.T. in elucidating true cases of P.T.S. We also describe a new surgical technique in the management of this condition.

\section{Clinical data}

The Victorian Spinal Injuries Unit serves the states of Victoria and Tasmania, and the southern part of New South Wales. Since its establishment at the Austin Hospital in 1956 more than 3500 patients have been treated. We have reviewed 21 patients who were diagnosed clinically as having P.T.S., all of whom had had significant cord injuries. (Table I).

Most cases were diagnosed at routine outpatient reviews, with only two presenting because of increasing disability. These patients all presented between April, 1983 and September, 1984.

\section{Clinical presentation}

Of the 21 patients suspected clinically of having P.T.S., 12 had complete spinal cord lesions. There were 11 quadriplegics, 7 thoracic and 3 thoraco-lumbar paraplegics (Table I). The mean period between initial injury and the onset of new symptoms was 101 months for incomplete lesions and 39 months for complete lesions. In all cases there was significant damage to the vertebral column at the time of initial injury. There were 4 female and 17 male patients, aged between 13 and 49 years at the time of the original injury. 
Table II Clinical and radiological findings

\begin{tabular}{|c|c|c|c|c|}
\hline Name & $\begin{array}{l}\text { Time since } \\
\text { accident } \\
\text { (months) }\end{array}$ & Symptoms & Neurological findings & C.C.T. Results \\
\hline E.W. & 102 & Nil & $\begin{array}{r}\text { R. + L.A. weakness } \\
\text { anaesthesia }\end{array}$ & C5 syrinx \\
\hline A.M. & 53 & $\begin{array}{l}\text { L.A. weakness } \\
\text { hyperhidrosis }\end{array}$ & C5 hypoalgesia & C4 syrinx \\
\hline R.W. & 24 & $\begin{array}{l}\text { R.A. pain/weakness } \\
\text { numbness }\end{array}$ & $\mathrm{C} 1-5$ hypoalgesia & brainstem syrin $x$ \\
\hline R.B. & 228 & $\begin{array}{l}\text { R.L. weakness } \\
\text { spasticity }\end{array}$ & $\begin{array}{l}\text { T11 hyperalgesia } \\
\text { T4-11 hypoalgesia }\end{array}$ & T9-C6 syrin $x$ \\
\hline T.L. & 120 & $\begin{array}{l}\star \text { R.A. numbness } \\
\text { hyperhidrosis }\end{array}$ & $\mathbf{N}$ & C5 syrinx \\
\hline J.W. & 3 & L.A. numbness & C8-T5 temperature loss & T5-C3 syrinx \\
\hline G.S. & 144 & 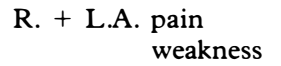 & $\mathbf{N}$ & C4-medulla syrinx \\
\hline J.B. & 10 & $\begin{array}{l}\text { L.A. pain } \\
\text { numbness }\end{array}$ & C3 hypoalgesia & $\mathrm{C} 2-\mathrm{T} 2$ syrinx \\
\hline S.H. & 18 & $\begin{array}{l}\star \text { R.A. numbness } \\
\text { hyperaesthesia }\end{array}$ & $\begin{array}{l}\text { C3 analgesia } \\
\text { T2 hypoalgesia }\end{array}$ & C2-T8 syrinx \\
\hline C.M. & 3 & $\begin{array}{l}\text { L.A. pain } \\
\text { weakness }\end{array}$ & T2 paraesthesia & C4-7 syrinx \\
\hline M.L. & 156 & $\begin{array}{l}{ }^{\star} \text { back pain } \\
\text { hyperhidrosis }\end{array}$ & $\begin{array}{l}\text { bilateral C8 } \\
\text { hyperalgesia }\end{array}$ & T5-C2 syrinx \\
\hline P.G. & 60 & $\begin{array}{l}\text { L.A. weakness } \\
\text { dyspneoea }\end{array}$ & $\begin{array}{l}\text { C4 complete } \\
\text { VC. } 1 \text { litre }\end{array}$ & C6-C3 syrinx \\
\hline L.M. & 102 & R. + L.A. weakness & $\begin{array}{l}\text { R.A. hypoalgesia } \\
\text { hyperaesthesia }\end{array}$ & spotty cord \\
\hline W.C. & 60 & $\begin{array}{l}\star \text { R.A. weakness } \\
\text { numbness }\end{array}$ & R.A. C2 hypoalgesia & NS \\
\hline D.T. & 3 & $\begin{array}{l}\text { neck pain } \\
\text { L.L. weakness }\end{array}$ & $\begin{array}{l}\text { C4-T9 hypoaesthesia } \\
\text { C3-T1 analgesia }\end{array}$ & NS \\
\hline J.F. & 120 & R.A. + L. spasticity & $\begin{array}{l}\text { C4 hypoaesthesia } \\
\text { weakness }\end{array}$ & NS \\
\hline K.C. & 30 & $\begin{array}{l}\text { pain/hyderhidrosis } \\
\text { R.A. clumsiness }\end{array}$ & C5-6 weakness & atrophic cord \\
\hline B.W. & 60 & $\begin{array}{l}\text { L.A. pain } \\
\text { hyperhidrosis }\end{array}$ & C2-6 hypoalgesia & $\begin{array}{l}\text { T1-3 syrinx } \\
\text { (below level of injury) }\end{array}$ \\
\hline G.T. & 46 & $\begin{array}{l}\star \text { L.A. pain } \\
\text { numbness }\end{array}$ & $\mathrm{N}$ & $\begin{array}{l}\text { C4-6 syrinx } \\
\text { spotty cord }\end{array}$ \\
\hline M.B. & & $\begin{array}{l}\text { L.A. pain/weakness } \\
\text { hyperaesthesia }\end{array}$ & C2-6 hyperalgesia & C4-5 syrinx \\
\hline A.C. & 24 & R.L. pain & T10 hypoaesthesia & atrophic cord \\
\hline
\end{tabular}

^ Exacerbated by straining/posture/repetitious movement

NS = No syrinx found

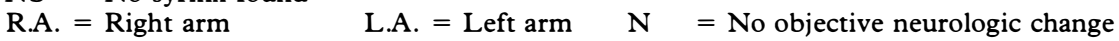

R.L. = Right leg L.L. = Left leg $\quad$ V.C. = Vital capacity

The most common presenting feature was pain (Table II). Sensory loss was the next most frequent symptom. In several cases, the patients complained of marked hyperaesthesia and hyperalgesia, which significantly reduced their functional capacity. A large number of patients had definite motor impairment, as opposed to functional weakness secondary to severe pain or hyperaesthesia. Symptoms were usually unilateral, however in three cases they were bilateral. No cases of Charcot's joints or orthostatic hypotension were found. The symptoms were constant except in 5 patients, who described worsening with 
straining, prolonged sitting or repetitive movement. One of these (M.L.) related the initial onset of symptoms to an episode of straining.

\section{Radiological techniques}

C.C.T. was performed in all cases, using a Siemens Somatom DR3 scanner. The patients were screened in the lateral decubitus position with a bolster under the loin as they were often mildly scoliotic. A lumbar puncture was then performed, usually at the 3rd or 4th lumbar vertebral level, without local anaesthetic, as this tended to aggravate muscular spasm. In the earlier cases isotonic metrizamide $(5-8 \mathrm{mls})$ was injected under image intensifier control and the patient was then maintained in a head down position for 2-5 minutes to allow cephalad distribution of the contrast material. Iopamidol has been used in recent cases after completion of this paper, and appears to have the same dynamics as metrizamide.

The following sequence of scans was then performed:-

1. immediate

2. 5-8 hours post injection

3. 24 hours post injection

The scans were made through the level of the injury and extended cephalad at least to the highest level of clinical involvement, and caudally to at least two vertebral levels below the injury site. In higher cervical lesions, at least one scan included the posterior fossa to assess the 4th ventricle. Lateral Cl-2 puncture was performed only when it was impossible to achieve adequate flow of contrast above the level of injury using a lumbar approach. Direct cyst puncture (endomyelography) with C.T. scanning was only performed in two cases in which equivocal information had been obtained by conventional methods.

\section{Operative procedure}

The surgery in this series was performed by two neurosurgeons. The surgical procedures used were:-

(a) Cord transection (complete lesions only-2 patients).

(b) Myelotomy (1 patient).

* (c) Syringo-subarachnoid shunt (2 patients).

(d) Syringo-peritoneal shunt (1 patient).

* (e) Syringo-subdural shunt (1 patient).

(f) Syringo-cisternal shunt (6 patients).

(g) Laminectomy (1 patient).

( One patient in each group underwent a subsequent syringo-cisternal shunt).

Procedures a, b, c, \& d have been well described elsewhere (Shannon 1981, Vernon 1983). The techniques of subdural and syringo-cisternal shunting, to our knowledge, have not previously been described in the management of P.T.S. The former was initially devised by one of the authors (J.M.C.) because adhesions made impossible the placement of the shunt catheter in the subarachnoid space in one particular case. Because of this particular problem and 
also because a number of catheters later became obstructed by adhesions, the technique of syringo-cisternal shunting was devised.

After a one to two segment laminectomy at the appropriate syrinx level, a soft, flanged, silastic Portnoy catheter was passed cephalad into the subdural space with the aid of a floppy guide wire. The tip of the catheter impinged on the arachnoid mater enclosing the cisterna magna which provided some resistance to the progress of the catheter. This resistance was easily overcome and the catheter advanced into the cisterna magna with an accompanying gush of pulsating C.S.F. down the tubing after the removal of the guidewire. The distal end of the shunt tubing was then placed in the syrinx cavity and the catheter secured to the dura mater. The passage of the catheter could usually be achieved with ease from the level of the syrinx; however in one case, because of dense adhesions, it was necessary to perform a C1-2 laminectomy to place the catheter tip into the cisterna magna under direct vision. Division of adhesions was not usually undertaken beyond that necessary for adequate exposure of the spinal cord because recurrent adhesions are unlikely to be prevented.

This procedure is well suited for cervical and upper thoracic syrinxes; it may be used for ones at lower levels by lengthening the standard $15 \mathrm{~cm}$ catheter with a connector and additional catheter tubing, or by using a longer catheter of the type used in ventriculo-atrial shunts. The position of the radio-opaque catheter tip can be varified by $x$-ray.

\section{Radiological findings}

In 15 of the 21 cases there were radiologically proven syrinxes (Table II) (Fig. 1). In the 6 cases where C.C.T. was negative for the presence of syrinxes, the cord was still seen to be obviously abnormal-these cases will hereafter be referred to as 'C.C.T. negative'. In 2 cases (L.M. \& G.T.) the cord was 'spotty' (Fig. 2). These may well be areas of myelomalacia (vide infra) (Williams 1981). The cord was atrophic in the other four. A syrinx extending below the level of the lesion was demonstrated in 1 case only. Two patients (G.S. \& R.W.) had syrinxes extending into the brainstem. The radiological extent of syrinx was not related to severity of initial injury. Patients M.L. and G. T. showed an immediate accumulation of contrast within the spinal cord substance. More often a slower pooling of contrast was evident-best seen in the 5 hour films. The 24 hour delayed films did not reveal the existence of any cord pathology not seen on the earlier scans. We did not demonstrate multiple syrinxes in any patient.

\section{Surgical management}

Twelve patients underwent surgery for P.T.S. (Table III). The reasons for conservative management in the nine others were as follows:-

1. Six were 'C.T. negative'.

2. One had symptoms felt to be unrelated to the presence of the syrinx (M.B.).

3. One spontaneously improved (B.W.).

4. One had no motor disability or objective sensory impairment (G.T.). 
Table III Results of surgery

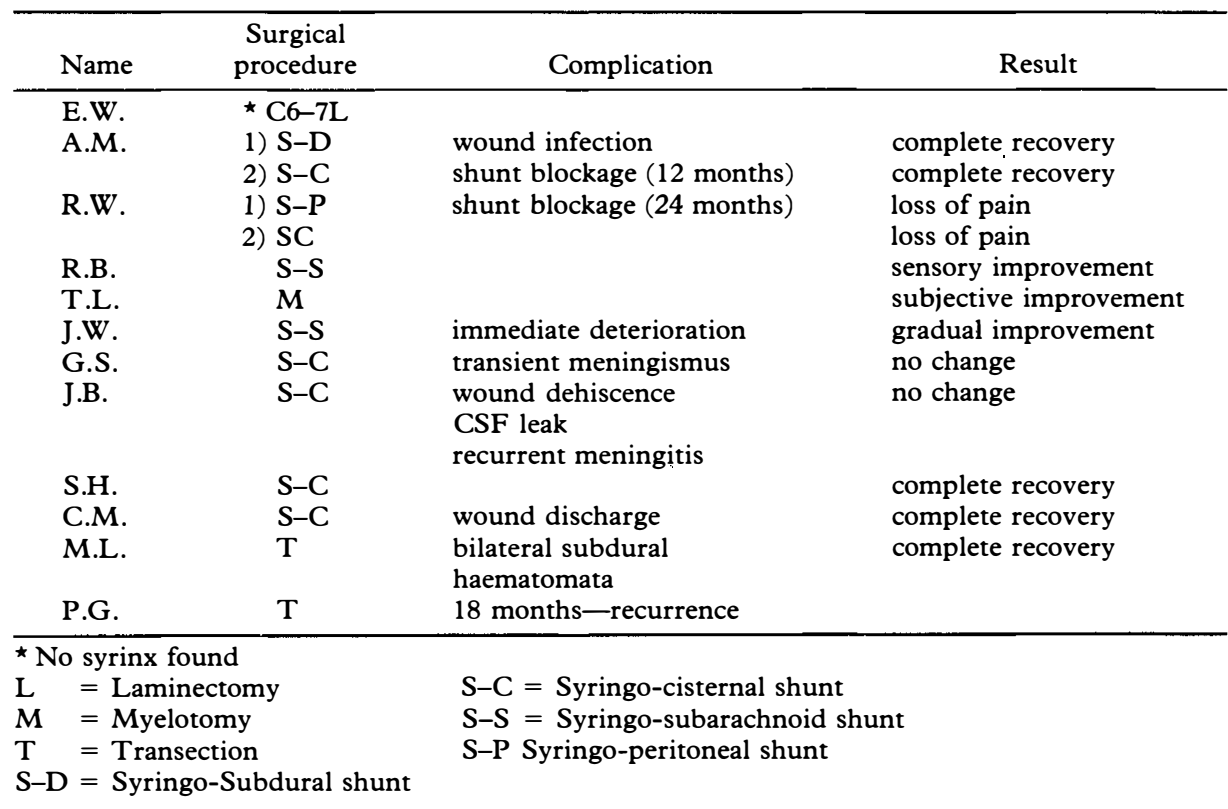

In all cases undergoing surgery, except one, the operative findings were consistent with the C.C.T. results. In this case (E.W.) the cord was normal externally, perhaps indicating that the syrinx was anteriorly situated or that it was too small to distend the cord. No definitive decompression procedure could be performed but this case will be closely followed for further evidence of neurological deterioration. In the two cases where immediate pooling of contrast within cord substance was seen, no macroscopic communication with the subarachnoid space was found at operation.

The details of each operation performed are listed in Table III. The results of surgery have been extremely encouraging. Seven out of eleven patients whose syrinxes were decompressed showed improvement after surgery, four of these being a complete resolution of all symptoms and signs and three showing loss of pain, improvement in sensation but little change in motor function. One (R.W.) showed complete resolution of pain, but no change in sensation or motor function. However this allowed a marked improvement in his functional capacity by allowing him pain-free use of his residual functioning muscles.

Three patients showed no improvement post-operatively but neither have they deteriorated further. One patient (J.W.) showed worsening of his condition in the post-operative period. Investigations demonstrated the shunt to be functioning adequately with no expansion of the original syrinx. We are unable to explain this situation but this type of deterioration has been well described in surgery for central canal syringomyelia. His neurological function had begun to improve on discharge. Two patients (A.M. and R.W.) developed a recrudescence of symptoms after initial improvement, 12 and 24 months respectively after surgery. Repeat C.C.T. on both patients demonstrated pools of contrast 


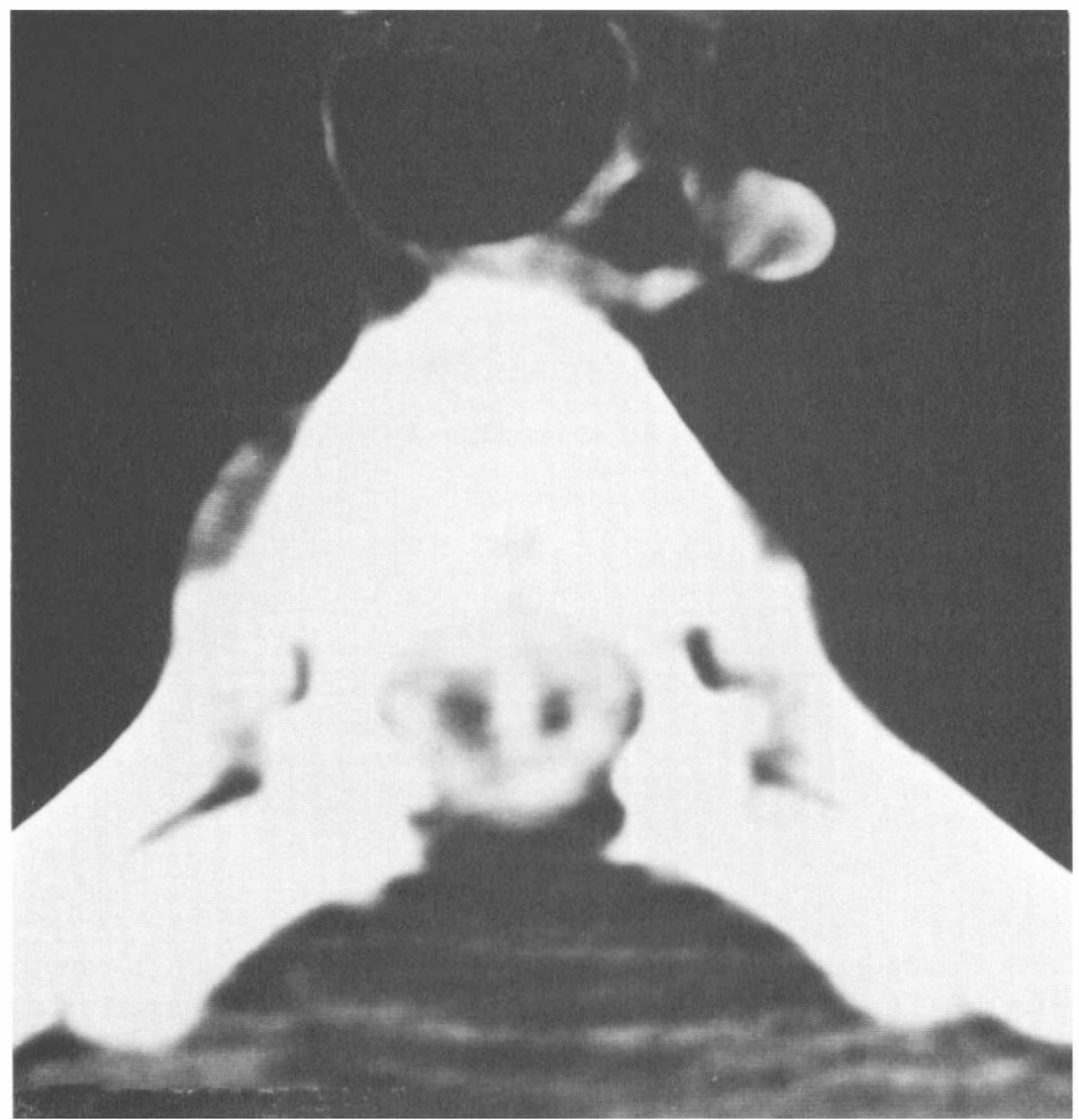

Figure 1 Large syrinx filled with contrast.

within the cord substance, indicating shunt blockage due to subarachnoid adhesions and the shunt was revised to a syringo-cisternal type. R. W. had an interesting operative finding, in that the syringo-peritoneal shunt was stenosed by bony regrowth of the $\mathrm{T} 1$ lamina, which had formed an osseous tunnel around the shunt catheter. This was at the level of a previous stabilising spinal fusion performed soon after injury. The syringo-peritoneal shunt was revised and a syringo-cisternal shunt was also created as a fail-safe mechanism. In both cases symptoms improved after the second operation.

There were only two significant post-operative complications (Table III). Case J.B. developed recurrent methicillin-resistant Staphylococcus aureus (M.R.S.A.) meningitis and later required surgery to close a defect in the dura. Case M.L. demonstrated a potentially lethal complication in that he developed bilateral subdural haematomata seven weeks after cord transection. This complication has been documented in spinal surgery and is possibly related to an abrupt lowering of the intracranial pressure secondary to intra-operative loss of C.S.F., though the patient was not operated in the sitting position. 


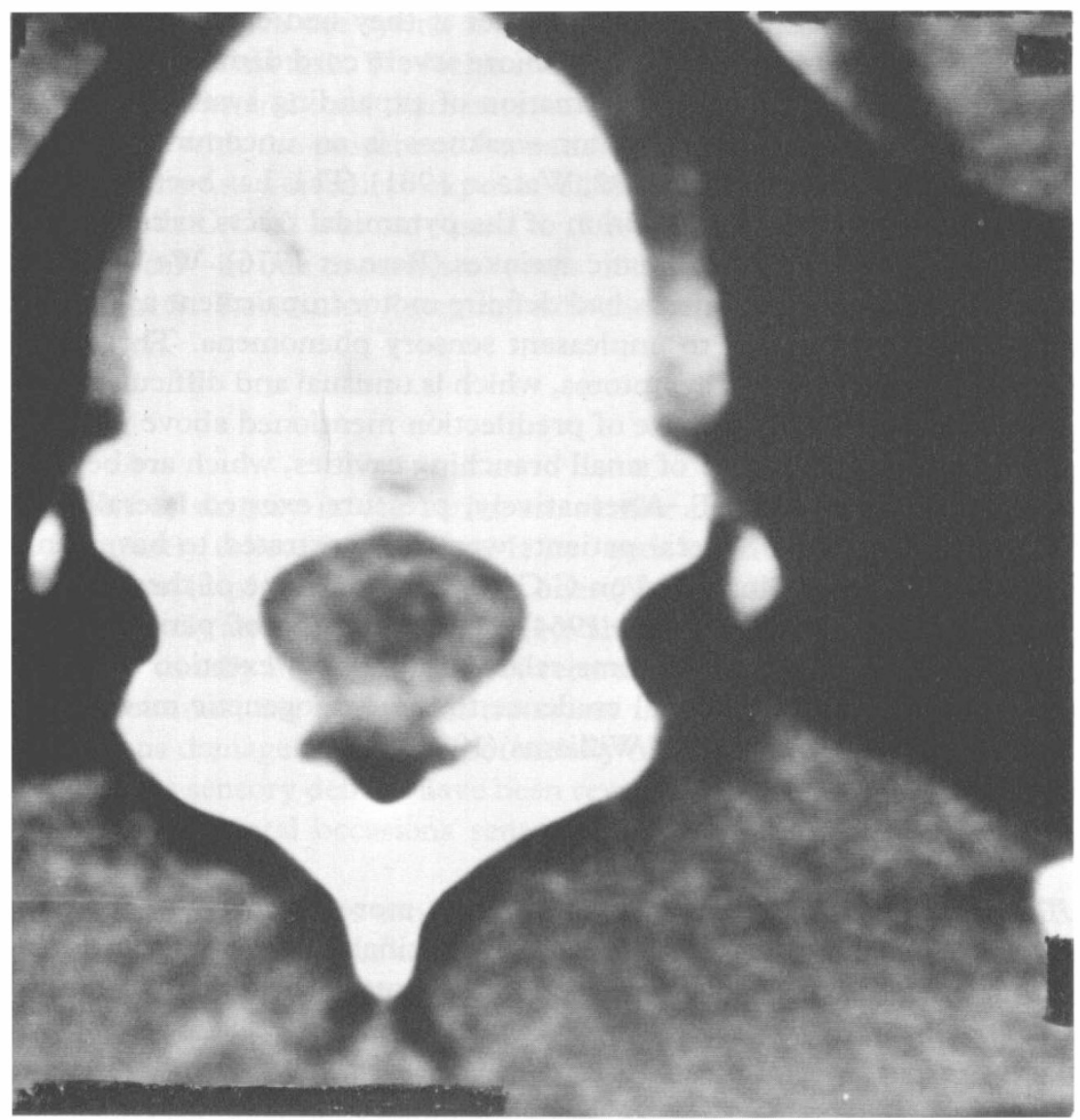

Figure 2 'Spotty' cord. No syrinx seen.

\section{Discussion}

\section{Incidence}

The overall incidence of this condition in our Unit is higher than that reported from other Units (Vernon, 1982). The fact that all these cases have presented within an 18 month period may indicate that our awareness of this condition is greater than previously and that our diagnostic tool (C.C.T.) is now much more effective. A high degree of awareness is mandatory in spinal patients, who develop musculo-skeletal pain and neurological problems for many reasons, e.g. spondylosis, spinal canal stenosis and osteoarthritis of weight-bearing joints. In addition, some patients are highly institutionalised and introspective and may present symptomatology which is inexplicable on organic grounds. For this reason we may previously have wrongly attributed new complaints to any of the above conditions; this should occur less frequently with the use of C.C.T.

\section{Clinical findings}

Our findings, in the main, were in accord with those of others, though we found 
that patients developed the condition earlier if they had complete spinal cord lesions rather than incomplete. Perhaps more severe cord damage leads to cystic degeneration which may procede formation of expanding systs (vide infra). It has been noted by others that motor weakness is an uncommon presenting feature (Shannon 1981, Vernon 1982, Watson 1981). This has been explained in terms of the relatively remote position of the pyramidal tracts in relation to the site of predilection of post traumatic syrinxes (Barnett 1976). We discovered a significant number of our patients had definite motor impairment as opposed to functional weakness related to unpleasant sensory phenomena. Three patients were shown to have bilateral symptoms, which is unusual and difficult to explain on anatomical grounds (if the site of predilection mentioned above is accepted) except by invoking the theory of small branching cavities, which are beyond the limits of resolution of C.C.T. Alternatively, pressure exerted laterally by the syrinx may explain this. Several patients were demonstrated to have centrally placed syrinxes in the spinal cord on C.C.T., however none of these developed orthostatic hypotension (Maynard 1964). The subgroup of patients who described worsening of their symptoms related to physical exertion or repetitive movements seems to lend clinical credence to the pathogenetic mechanisms of syrinx enlargement proposed by Williams (1981).

\section{Radiology and pathology}

C.C.T. has allowed us to study this condition more extensively. Six patients with classical presentation of P.T.S. had no identifiable syrinx on C.T. scan but had either atrophic or 'spotty' cords. These 'spotty' areas may represent the areas of myelomalacia described by Williams, which he feels are secondary to haemorrhage or ischaemic necrosis at the time of injury. They subsequently liquefy and, by mechanisms not yet fully elucidated, enlarge to form macroscopic syrinxes (Williams 1981). We feel that these 'C.C.T. negative' cases may represent an early stage of this progressive condition, with spinal cord pathology barely discernible using conventional imaging. These small areas of degenerative cord may be responsible for the clinical picture, as it is well recognised that the site and size of a syrinx bear no relationship to the severity of symptoms (Shannon 1981, Vernon 1982). Those patients with abnormal cords may develop a more easily definable syrinx at a later date. Thus, to establish the natural history of P.T.S. it will be necessary to perform C.C.T. on a group of spinal cord injured patients soon after injury and then at set intervals over many years. This will enable the radiological appearances to be correlated with the clinical findings and enable the identification of C.C.T. features which may indicate a pre-disposition to later syrinx formation.

Previously, in this condition, myelography only revealed abnormalities if the spinal cord was expanded, and exploratory surgery allowed us to examine only the region of injury. C.C.T. allows us to identify syrinxes extending below the level of the initial cord injury (Quencer 1983, Williams 1981). These syrinxes may be as clinically important as ascending syrinxes, especially in incomplete spinal cord lesions; thus we urge that the term 'ascending cystic myelopathy' be discarded.

In describing the dimensions of the syrinx we record the position, diameter 
and the area in which the syrinx is closest to the surface of the spinal cord, to aid the surgeon in his task. We feel it is of little purpose meticulously to measure syrinx dimensions and cord diameters, as the size of the syrinx has clearly been shown to vary with the posture of the patient (Quencer 1983). Likewise, sagittal reconstructions are a needless expense of time and labour. Endomyelography combined with C.C.T. was only used in 2 cases where standard C.C.T. results were equivocal-in our experience it was of little help in elucidating the situation. Magnetic Resonance. Imaging will have further ability to demonstrate this condition.

\section{Surgery}

The results of surgery in our series are similar to others in that pain was the most frequently relieved symptom. It has been maintained that motor deficits are more often improved than sensory ones (Vernon 1983) and also that sensory loss is very rarely altered (Shannon 1981). Shannon has stated that this is because the syrinxes usually lie in the area between the dorsal horn grey matter and the posterior columns, i.e. pyramidal tracts are involved much later than sensory ones and thus damage to them is potentially more reversible. We have not seen this pattern, as sensory deficits have been reversed as commonly as motor deficits and indeed on several occasions sensory abnormalities have been completely reversed by surgery.

Results of surgery in this condition were first detailed by Barnett in 1973, but even now we are still unclear as to the natural history of this disorder or whether surgery influences its progression in the long term. Certainly, the short term results of surgery are excellent. In our series, $91 \%$ of patients were improved or had their neurological deterioration halted by surgery. It is generally felt that failure to operate will result in eventual progression of the disorder. This is not absolute, as one of our patients (B.W.) underwent spontaneous resolution of symptoms and remains well. In Griffith's series no patient underwent surgery, as none had progressive neurological deterioration (Griffiths 1981). A trial comparing surgery with conservative management would be difficult to conduct and unethical in view of the potentially catastrophic results of continued neurological deterioration, particularly in the cervical cord. Surgery is indicated in all cases where progressive neurological deterioration is thought to be due to a radiologically proven syrinx. In addition, we believe there is an absolute indication in those patients with symptoms, whose syrinx lies in the cervical cord. The risk of progressive disability leading to respiratory failure is too great to allow a 'wait and see' policy. A relative indication for surgery exists in patients who are distressed by pain but have no progressive clinical signs.

Of the surgical procedures available two are, we believe, most appropriate. For thoraco-lumbar syrinxes, the syringo-peritoneal shunt is the operation of choice, although it may often prove to be technically difficult. For higher thoracic and cervical syrinxes, the syringo-cisternal shunt has proved to be very effective and to have low morbidity. This is the only shunt procedure which has not been complicated by shunt catheter blockage and syrinx recurrence. We believe this is far superior to simple syringo-subarachnoid shunting, in theory and in practice, as the catheter tip is less likely to be occluded by adhesions 
when placed in the spacious cisterna magna. It also allows closure of the theca, which is not perfectly achieved in syringo-peritoneal shunts. Potential risks of blind passage of the catheter into the posterior fossa are minimal in careful hands.

The point at which shunting was performed was determined by:-

1. Neurological and functional disability.

2. Level of maximum cyst diameter on C.C.T.

3. The desire to minimize damage to functioning neural tissue.

Cord transection has been performed but in general has little to commend it. Even in cases where very large syrinxes were transected to leave a capacious portal for drainage (P.G.), the symptoms have progressed, presumably as a result of adhesion formation. Recrudescence of symptoms in shunting procedures can occur, but is not necessarily due to shunt blockage as maintained by Vernon (1983). It may be due to development of a new syrinx (perhaps enlargement of a pre-existing small additional syrinx), the shunting of one syrinx only in the presence of multiple syrinxes, loculated syrinxes or haemorrhage into a syrinx.

\section{References}

Barnett HJM, Jousse AT 1976 Post Traumatic Syringomyelia (Cystic Myelopathy). Handbook of Clinical Neurology, North Holland Publishing Co. Vol. 26 p. 113-155.

Griffiths ER, McCormick CC 1981 Post Traumatic Syringomyelia (Cystic Myelopathy). Paraplegia 19:81-89.

MAYNARD FM 1964 Post Traumatic Cystic Myelopathy in Motor Incomplete Quadriplegia Presenting as Progressive Orthostasis. Archives of Physical Medicine and Rehabilitation Vol. 65:30-32.

QuenCer RM, Green BA, Lismont FJ 1983 Post Traumatic Spinal Cysts: Clinical Features and Characterisation with Metrizamide Computed Tomography. Radiology 146:415-423.

SHANNON N 1981 Investigation and Treatment of Post Traumatic Syringomyelia. fournal of Neurology, Neurosurgens and Psychiatry 44:35-42.

Vernon JD, Silver JR, Symon L 1983 Post traumatic Syringomyelia: The Results of Surgery. Paraplegia 21:37-46.

Vernon JD, Silver JR, Ohry A 1982 Post Traumatic Syringomyelia. Paraplegia 20:339-346.

Watson N 1981 Ascending Cystic Degeneration of the Cord after Spinal Cord Injury. Paraplegia 19:89-95.

Williams B et al. 1981 Syringomyelia as a Sequal to Traumatic Paraplegia. Paraplegia 19:67-80. 